\title{
MÁS VIVIENDAS, MENOS CIUDAD. Las transformaciones recientes en el corredor norte del AMBA
}

\author{
Viviana Colella, Victoria Castillo \\ Universidad Nacional de General Sarmiento \\ Directores: Alicia Novick, Joaquín Sabaté \\ vcolella@ungs.edu.ar/vic sole@hotmail.com
}

\section{Resumen}

En las últimas tres décadas, la ribera norte del AMBA ha cambiado por completo. Estos tejidos suburbanos, de usos mixtos, residenciales, recreativos y logísticos, se fueron homogeneizando morfológica, social y funcionalmente, con la llegada de emprendimientos inmobiliarios destinados a los sectores de mayor poder adquisitivo. En este marco, este trabajo se cuestiona acerca de las características espaciales de estos cambios y la calidad del espacio urbano resultante, en tanto escenario de las experiencias cotidianas de los habitantes. Para esto, se analizan dos áreas que han sido fuertemente impactadas por estos cambios en los municipios de Tigre y Vicente López.

Palabras clave: Transformaciones territoriales - Tejidos suburbanos - Fachadas urbanas - Desarrollos residenciales

\begin{abstract}
In the last three decades, the north coast of the AMBA has completely changed. These suburban fabrics with mixed land uses such as residential, recreational and logistics, were morphologically, socially and functionally homogenized, with the arrival of real estate developments destined to greater purchasing power sectors. In this framework, this paper inquiries about the spatial characteristics of these changes and the quality of the resulting urban space as a scenario for daily experiences of the inhabitants. For this, two areas that have been strongly affected by these changes are analyzed in Tigre and Vicente López municipalities.
\end{abstract}

Keywords: Territorial transformations - Suburban fabrics - Urban facades - Residential developments 


\section{INTRODUCCIÓN}

En los últimos años, el paisaje ribereño norte ha cambiado por completo. Los barrios suburbanos, de población de nivel adquisitivo medio y bajo, con usos ampliamente heterogéneos, son impactados por emprendimientos inmobiliarios destinados a los sectores de mayor poder adquisitivo, rodeados de muros, cámaras de vigilancia y seguridad privada.

Desde muy diversas interpretaciones, distintas investigaciones (De Mattos, 2010, Sassen, 1999, Castells, 1995) han examinado esas cuestiones, analizando principalmente el impacto territorial de los procesos globales, las relaciones de disputa entre los actores involucrados en torno a estos territorios, o las consecuencias ambientales de estos desarrollos residenciales. Sin embargo, poco se ha avanzado en el estudio de sus particularidades morfológicas y sus consecuencias en el espacio urbano.

Si bien las nuevas tipologías residenciales son producto de acciones individuales de reemplazo parcela a parcela, sostenemos que se pueden reconocer características morfológicas semejantes, entre ellas, un incremento de la discontinuidad espacial que impacta en el espacio urbano y, así, provoca una pérdida de dinamismo del espacio público de la calle.

Las "fachadas" urbanas, previo a la década de 1990, presentan una continuidad que, a diferencia de ciudades europeas, está dada por una sucesión de espacios de transición entre el adentro y el afuera, más que por edificaciones alineadas. Esta porosidad de las "fachadas" suburbanas desdibuja el límite con el afuera; se resignifica la relación entre lo público y lo privado, acercando la calle, asumiéndola, en la práctica, como una extensión del adentro. En contraposición, los cercos opacos que rodean las nuevas tipologías residenciales estrechan el espacio urbano, limitan la visual y homogeneizan el paisaje. Puesto que los procesos de la última década tienen un gran impacto en los tejidos interiores, la presencia de los muros y, de este modo, la discontinuidad espacial, modifican las formas de habitar el espacio urbano.

Es en este punto, que resulta relevante releer los paisajes de las nuevas configuraciones urbanas y analizar los cambios que proponen estas nuevas "fachadas urbanas". Así, las preguntas que guían este trabajo son ¿cuáles son los cambios espaciales que producen las nuevas tipologías residenciales? y ¿cuál es la experiencia que aportan estos nuevos tejidos residenciales a quienes transitan la ciudad?

En las últimas tres décadas las áreas de mayor transformación en el AMBA fueron la costa norte, a partir de emprendimientos inmobiliarios de urbanizaciones cerradas y condominios con amenities, y las periferias degradadas, con la extensión de asentamientos informales y complejos de viviendas sociales, de loteos unifamiliares en tejidos regulares.

En este trabajo interesa centrarse en las nuevas formas y tipologías que se proponen en la costa norte, que permita comprender los procesos de densificación que caracterizaron los últimos años. Para esto, nos proponemos analizar los dos extremos de ese territorio, la zona más periférica y la más cercana a la ciudad de Buenos Aires, ambas de gran transformación. En primer lugar, identificamos un sector de reciente transformación en la desembocadura del río Reconquista, en Rincón de Milberg, Municipio de Tigre. El curso de agua divide el centro histórico del municipio y una zona de bañados, donde se lleva a cabo durante el siglo XX un proceso de urbanización por parte de sectores populares. En forma paralela, se instalan marinas sobre la costa del Reconquista, que en los últimos cinco años son reemplazadas por conjuntos residenciales multifamiliares cerrados. En segundo lugar, el área seleccionada corresponde a la calle Bartolomé Cruz, una arteria que sólo existía parcialmente y que es abierta en el marco de las grandes transformaciones que ocurren en Vicente López, con el arribo de torres de viviendas y oficinas.

En ambos casos, se analizan los cambios en el parcelario, el trazado y lo edificado, en relación con las características del espacio urbano y las regulaciones que los han enmarcado, a través del redibujo intencionado de fotografías satelitales de cuatro momentos: 1987 y 1995 provenientes de Geodesia, provincia de Buenos Aires, y 2004 y 2016, extraídos de la base Google Earth. Además, se analiza información proveniente de diversas fuentes documentales (normativa urbanística, desarrolladoras y comercializadoras inmobiliarias, estudios de arquitectura, medios de comunicación) así como entrevistas de referentes clave, que permiten reconstruir los procesos por detrás de esos nuevos hechos urbanos. 


\section{CARTOGRAFÍAS Y FORMAS URBANAS}

Si examinamos las formas de crecimiento del AMBA, no es difícil identificar que crece, desde sus inicios, en forma extensiva, primero siguiendo los ejes de urbanización (caminos reales, ferrocarriles y avenidas) y, luego, con la política de "lotes baratos"1 y subsidios del transporte automotor, que impulsa la ocupación de las áreas intersticiales entre dichos ejes. A partir de la década de 1990 la evolución de la mancha urbana va adoptando otras formas que reencuentran las que en otras latitudes se caracterizan como ciudad difusa (Indovina, 2004), metápolis (Ascher, 2004), global (Sassen, 1999), ciudad informacional (Castells, 1995), postmetrópolis (Soja, 2008) o lo urbano generalizado (De Mattos, 2010).

En este punto, y más allá de la diversidad de las propuestas, los referentes del urbanismo y la arquitectura, retoman los alcances de la investigación proyectual y de las lecturas interpretativas del territorio, para dar cuenta de procesos, reglas formales y patrones urbanos que intentan recuperar el conocimiento de las particularidades locales. Por detrás de estas investigaciones encontramos algunos denominadores comunes. En primer lugar, consideran que más allá de las cuestiones estructurales que en cada época atraviesan todas las ciudades y las ideas urbanísticas, la formulación de instrumentos de transformación territorial requiere del conocimiento de la morfología de cada ciudad, pues es allí donde radican las soluciones a sus problemas. En segundo lugar, entienden que el estudio de las formas urbanas produce conocimiento. En tercer lugar, consideran que los nuevos patrones urbanos se articulan con las formas existentes.

Estos estudios, que forman parte de una secuencia de investigaciones y trabajos que se inicia en la tendenza italiana, realizan un gran aporte acerca de la mirada proyectual sobre el territorio (Sainz Gutierrez, 2006), a través del análisis de los cambios formales de los elementos urbanos y sus relaciones. Esta mirada es compartida posteriormente por el Laboratorio de Urbanismo de la Universitat Politecnica de Catalunya que interpreta el territorio, desde una lectura intencionada, que, a partir de elementos (parcelario, trazado urbano, infraestructura), permite desvelar la lógica de construcción de cada territorio (Solà-Morales i Rubio, 1997; Font, Llop y Villanova, 1999). De este modo, mediante el análisis de las relaciones entre los elementos urbanos (edificación, parcelas, manzanas), se reconocen las características formales de los cambios.

Desde la perspectiva de estos estudios, la ruptura con los patrones de urbanización previos, el desplazamiento de las ciudades compactas y mono-céntricas a la idea de red, las nuevas tipologías residenciales y comerciales, y los espacios de oportunidad en áreas obsoletas aparecen como características de los cambios recientes pero también como categorías para comprender los espacios en que la disciplina urbanística puede accionar. En esos términos, estos trabajos permiten reconocer características morfológicas que se generan a partir de los cambios recientes, como la dispersión, la discontinuidad, el policentrismo, la fragmentariedad del proceso proyectual de los desarrollos de vivienda y comercio, y su falta de permeabilidad o porosidad. Esto se traduce en una pérdida de calidad urbana (Llop Torne, 2008) a causa de que las características de la nueva morfología se apartan de los principios de urbanidad que los instrumentos de planificación pretendían imprimir a las ciudades europeas del siglo XX: la compacidad, obtenida a partir de la contigüidad edilicia y una densidad media; la complejidad, producto de la mixtura funcional y tipológica; y la cohesión social, con la convivencia de diversos sectores sociales (Sabate, 2013).

En este contexto, consideramos que la ciudad actual, fragmentada, dispersa, discontinua, plantea la necesidad de comprender las características del espacio urbano resultante de esos procesos de transformación reciente. Es decir, requiere una mirada integral desde ese espacio que queda por fuera del ámbito privado de las parcelas y las manzanas: el espacio de la calle que divide lo público de lo privado, permite el desplazamiento, articula diferentes partes de la ciudad y a la ciudad con el territorio, establece áreas con jerarquías diferentes, es decir, que permite el funcionamiento del objeto urbano. Pero además, la calle es el lugar de interacción social, es el espacio de lo cotidiano. Por tanto, en una ciudad que se construye a través de fragmentos, donde el espacio público es lo residual, es lo que queda al construirse los emprendimientos residenciales, comerciales y de servicios detrás de altos muros, resulta relevante retomar la mirada de Secchi (2014) acerca de la calle, como límite que separa y, a la vez, lugar que une.

El análisis de la ciudad desde la calle ha sido abordado por algunos autores. Nos interesa retomar dos estudios, uno clásico que analiza la calle desde el recorrido resaltando la mirada de quien la transita

\footnotetext{
${ }^{1}$ Política pública que impulsó la venta de lotes sin servicios en las áreas periféricas de Buenos Aires.
} 
cotidianamente, y otro reciente que enfatiza su relación con las edificaciones que la limitan y conforman, a la vez. En primer lugar, nos referimos al trabajo de Cullen (1974), quien registra recorridos urbanos a través de distintas técnicas: de plantas que dan cuenta de las formas urbanas y de croquis sucesivos que muestran la atmósfera de esos lugares; esta forma de reconstruir un recorrido permite acceder a la relación entre el espacio urbano y quienes lo habitan cotidianamente. En segundo lugar, otros trabajos más recientes (Quan Lui, Ziyu Tong, 2016) ponen el foco en los límites del espacio urbano, las "fachadas de la ciudad" que enmarcan los recorridos que se emprenden cotidianamente en ella, se conforman por una sucesión de límites que se materializan en el encuentro entre lo privado y lo público.

\section{RECORRIDOS URBANOS}

Sobre una retícula ortogonal que aparentemente se extiende en forma regular y casi inmutable sobre el territorio del AMBA, se producen operaciones que generan diferencias en el plano, como los quiebres en las líneas de calles, las áreas de usos predominantes introducidas por la zonificación, las diferencias en los anchos de las calles que jerarquizan algunas sobre otras, los procesos de loteos fragmentarios que cambian o cortan la continuidad de las calles, las manzanas en " $X$ " que proponen parcelas de distintos tamaños a lo largo de la cuadra, la convivencia de tejidos de distintos períodos que responden, entonces, a diversas normativas, la normativa que estipula retiros mínimos de frente (y laterales según el ancho de la parcela). Estas características del proceso de construcción del AMBA, que dejan huellas en los planos de estos territorios, generan situaciones particulares, acontecimientos en el recorrido de esos paisajes urbanos heterogéneos.

En ese escenario, en los últimos años se produce un reemplazo parcela a parcela con la llegada de nuevos productos inmobiliarios de usos residenciales. Las parcelas más grandes, con usos no residenciales, son las que ejercen menos resistencias a los cambios. Estos objetos arquitectónicos se piensan y construyen como objetos en sí mismos, rodeados de grandes muros que los separa de la ciudad.

En ese contexto, los límites del espacio urbano, aquellos que enmarcan los recorridos que se emprenden cotidianamente por la ciudad, adquieren particular relevancia.

\subsection{Rincón de Milberg: desarrollos multifamiliares cerrados y tejidos suburbanos}

El río Reconquista constituye, en su desembocadura en el río Luján, el límite entre las localidades de Tigre y de Rincón de Milberg, ambas en el municipio de Tigre. Toda el área quedó excluida del reparto de suertes de chacras que Juan de Garay hizo al momento de la fundación de Buenos Aires, por ser un área de bañados. Sobre la desembocadura del Reconquista, en su orilla sur, había un fondeadero natural entorno al que creció un caserío de adobe, que posteriormente tomaría el nombre del río Las Conchas (actual Reconquista) y que fue, paulatinamente, poblándose y ganando gran dinamismo durante la segunda mitad del siglo XVIII. Este pequeño asentamiento irregular fue extendiéndose entre la actual ruta provincial (RP) 27 y el río Luján. Un fuerte temporal arrasó en 1820 con la zona, y modificó el curso del Reconquista, abriendo un nuevo brazo, el actual río Tigre, sobre un zanjón prexistente, y dejando al Reconquista en su cuenca baja, con muy poco caudal. Con el puerto, entonces, inutilizado, el río Tigre fue convirtiéndose en el nuevo atractor de la zona. Entre las quintas existentes en este territorio que quedó conformado entre los ríos Reconquista, Tigre y Luján, como una suerte de isla triangular, se fueron asentando aserraderos, astilleros, comercios y talleres, y posteriormente, clubes náuticos y guarderías marinas.

En la orilla norte del Reconquista, mientras tanto, se localizaba un monte de talas, que en las épocas de crecida quedaba completamente bajo el agua y cuando ésta se retiraba, era surcada por gran cantidad de arroyos y lagunas. Esta tierra, entonces propiedad de López Camelo, fue comprada por el matrimonio 


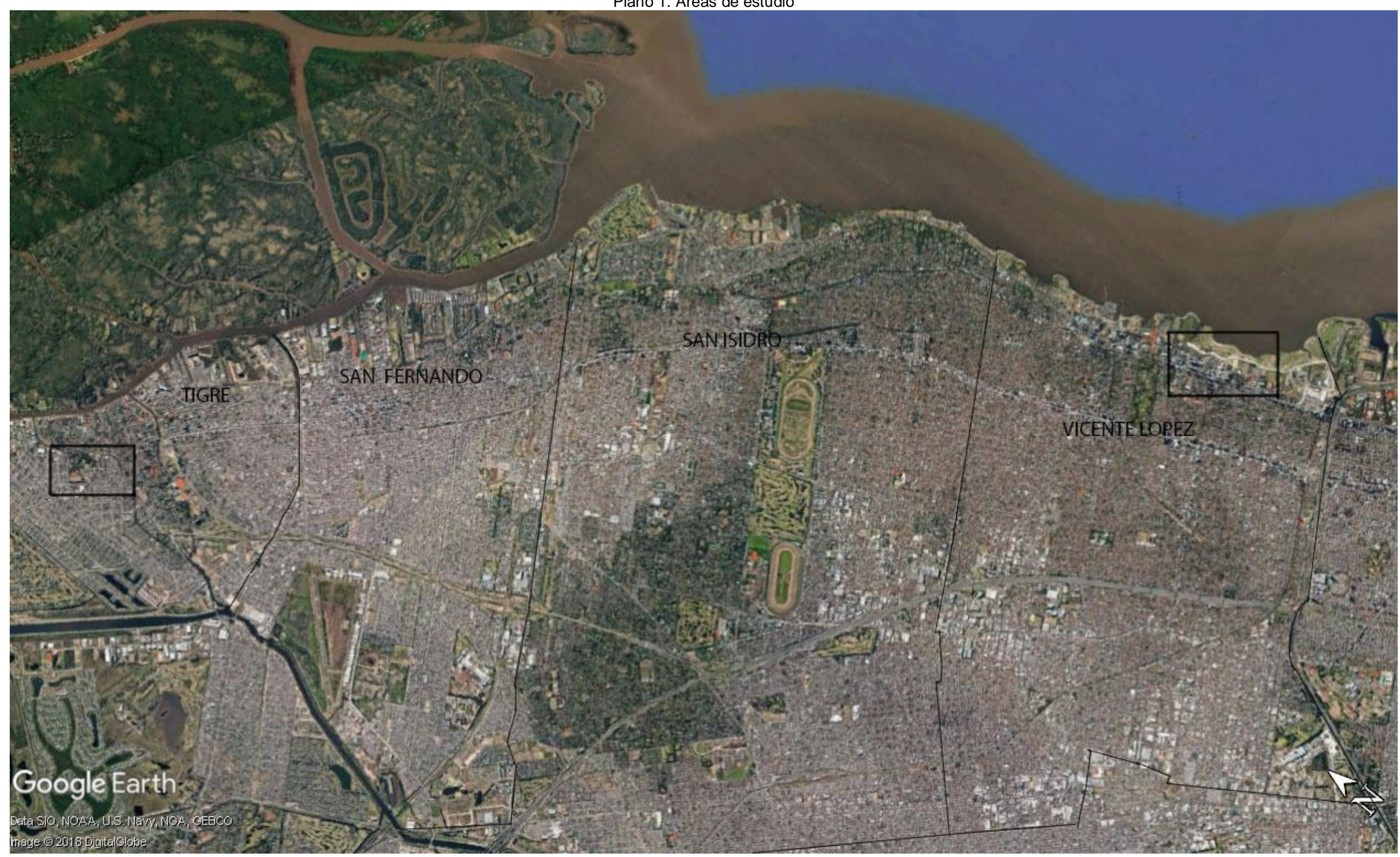

Fuente: elaboración propia (2018), sobre base Google Earth 
Milberg en 1856, quien nombró El Rincón, al rancho ya existente en la propiedad, de donde procede el nombre de la actual localidad. A los pocos labradores que convivían con las frecuentes crecidas se sumaron los "quinteros", a quienes Milberg alquilaba viviendas y retenía parte de sus ganancias por explotar la tierra, en actividades agrícolas, fábricas de ladrillos, secaderos de cueros, entre otros. Así, estos fueron los primeros pobladores de los bañados.

Con los consecuentes loteos y subdivisiones por herencia, fue poblándose muy lentamente el área, con quienes resistían las difíciles características del lugar y que estaban dispuestos a convivir con el agua que frecuentemente ocupaba gran parte del territorio. Esas crecidas convertían las calles de tierra en arroyos, y el puente que cruzaba el Reconquista, cerca del antiguo puerto, era la única conexión con el centro. La vida en esta zona nunca fue fácil, y la informalidad y precariedad de las viviendas de los pobladores que a lo largo del siglo XX fueron asentándose en la zona, el acceso al agua sólo a través de canillas comunitarias en cada barrio, o la falta casi total de equipamientos, no lo facilitaban. Con las características del territorio, cada loteo, cada ocupación, fue conformando un área con amplia heterogeneidad de manzanas y parcelas. Las viviendas de madera sobre pilotes, y posteriormente algunas de cartón, iban convirtiéndose en viviendas sólidas con el esfuerzo de las familias que las autoconstruían a lo largo de los años.

Con las mejoras de la Autopista Panamericana, los acceso a Tigre, y la RP27, así como de los espacios públicos entorno a los cursos de agua, el área sufrió grandes transformaciones que iniciaron a partir de 1990 y se profundizaron en las décadas siguientes. A partir de 2011, inició un proceso de transformación en la zona, con una nueva propuesta de uso residencial multifamiliar, los condominios, que dos años después, ya eran presentados en distintos medios de comunicación como las nuevas tipologías elegidas por los desarrolladores inmobiliarios por su menor costo de inversión inicial.

En este marco, se seleccionó un recorrido en la zona de mayor transformación, iniciando en la avenida Liniers, en la zona más histórica del municipio, cruzando el río Reconquista por la avenida José C. Paz y rodeando el sector de condominios.

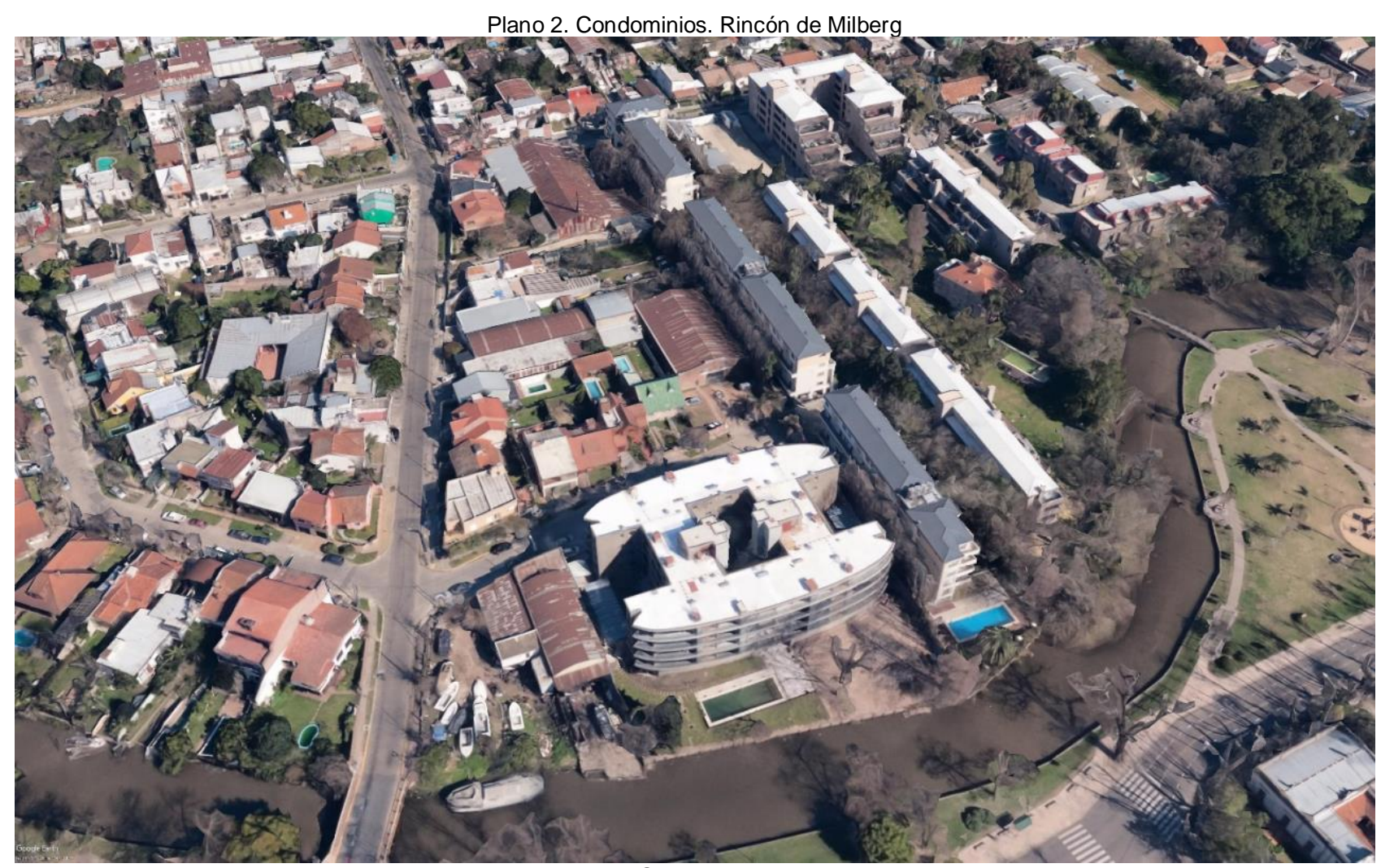

Fuente: Google Earth, 2018 
Plano 3. Croquis sucesivos

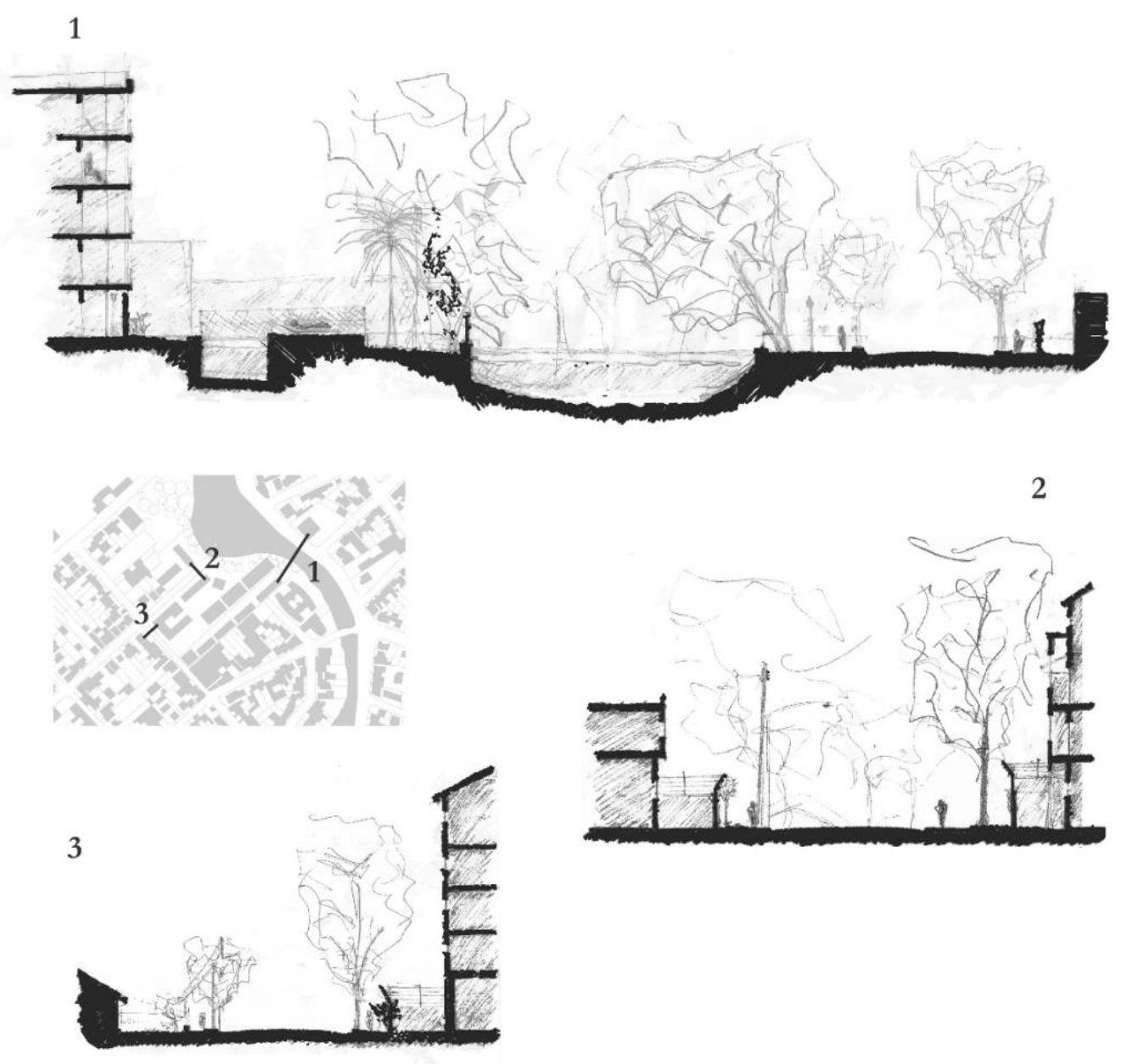

Fuente: elaboración propia (2017) 


\subsubsection{Límites administrativos. Lo público - lo privado}

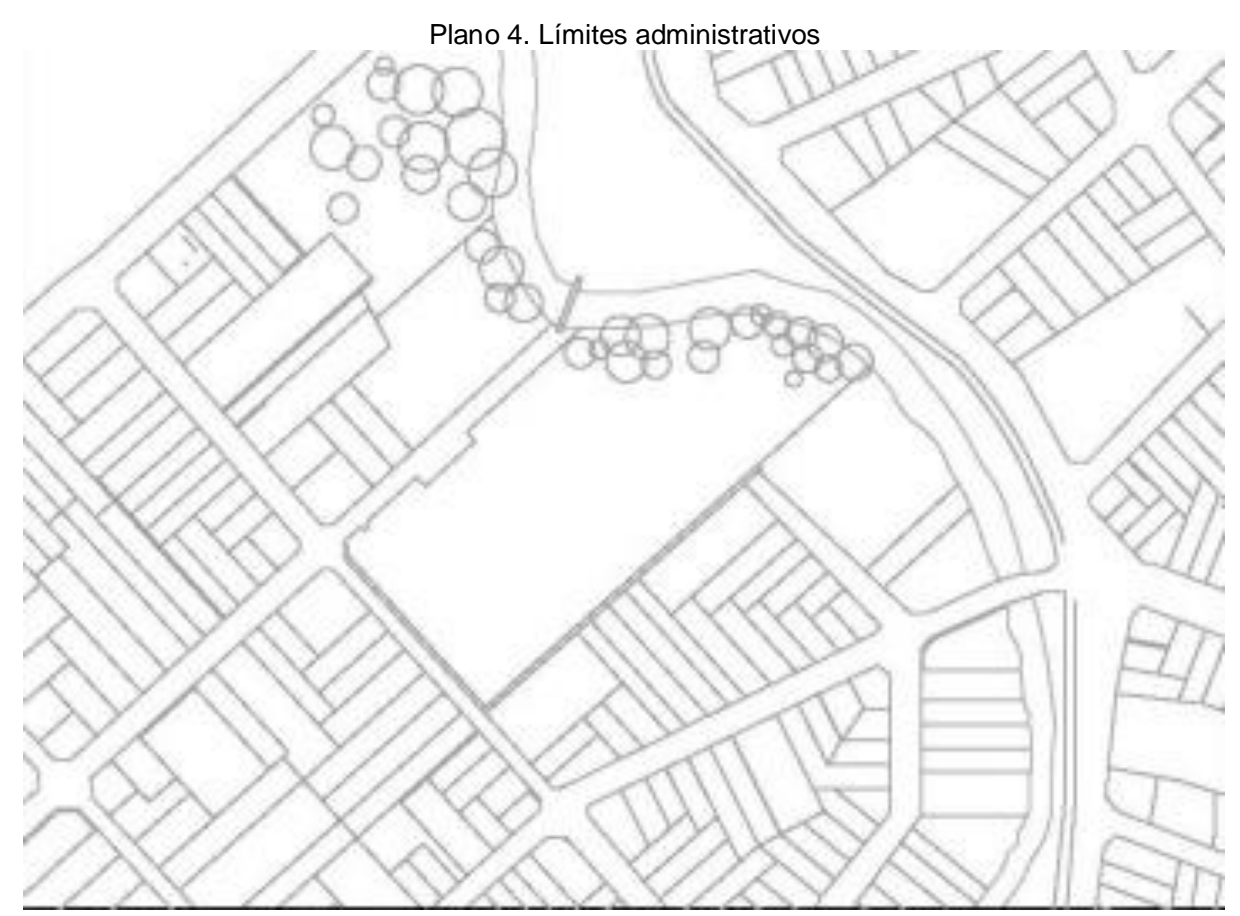

Fuente: elaboración propia (2017), en base a Google Earth

Las diversas lógicas de construcción de un área ya consolidada, han dejado huellas en el paisaje de esta zona, que se traduce en una heterogeneidad tipológica y una diversidad de relaciones entre las edificaciones, la parcela y la calle. Esta heterogeneidad también responde a la diversidad de formas de manzanas y parcelas, producto de un trazado irregular que busca articular la trama ortogonal de las áreas más consolidadas con la sinuosidad del río Reconquista, que atraviesa la zona. Asimismo, un área que antiguamente fue un bañado ha dejado también huellas de antiguos cursos de agua temporales, que aparecían sólo en épocas de crecidas del río, y que se fueron ocupando paulatinamente.

El trazado del área donde se localiza la zona de estudio es, en general, regular, con manzanas cuadradas, puesto que forman parte del ejido municipal. Las calles se cruzan ortogonalmente y terminan en forma perpendicular al río. Gracias a esta regularidad del trazado, aún con las particularidades del territorio, las manzanas son cuadradas con un parcelario en " $X$ ", característico del AMBA. Se observan parcelas de mayor tamaño en algunas manzanas, aquellas que están ocupadas por usos no residenciales. Las manzanas localizadas en los bordes del área tienen formas diversas ya que se adaptan a las formas del río sobre el que se emplazan.

En el extremo nordeste se localiza el área de estudio; allí el río realiza varias curvas que provocan una mayor irregularidad en el trazado, y, por tanto, en las manzanas y parcelas. Además, la calle José C. Paz, parte del recorrido en estudio, forma una diagonal para poder continuar la Avenida del Libertador, que conecta con el centro del Partido, por lo que las manzanas se adaptan a la introducción de esta particularidad dentro de un trazado regular.

La subdivisión en " $X$ " promueve tamaños de lotes distintos a lo largo de una misma cuadra; la profundidad de los mismos cambia entre aquellos que se localizan en las esquinas y los que se ubican a mitad de cuadra. Además de las parcelas de mayor tamaño destinadas a usos recreativos, productivos o de servicios, encontramos parcelas de dos tamaños. La mayoría tiene un mínimo de $10 \mathrm{~m}$, producto de fraccionamientos realizados a lo largo del siglo XX previos al Decreto Ley 8912/77, pero también, cuadras enteras o parcelas esparcidas en las manzanas cercanas al río Reconquista, con un ancho de $8.66 \mathrm{~m}$, característico de las primeras subdivisiones del AMBA, y tributarios de las medidas de lotes en época colonial. El primer tipo compone en particular el área de estudio pero con importante presencia de grandes parcelas, antiguamente guarderías náuticas y de usos productivos. Los cambios en los anchos de las parcelas que responden a momentos diversos, algunas manzanas alineadas con formas diferente al resto, 0 algunos trazados que incluyen calles internas que terminan en cul-de-sac, marcan indicios de fragmentos que fueron loteados en conjunto. 
Las parcelas lindantes al río se ubican en forma perpendicular a él. Lo mismo sucede con las frentistas que tienden a localizarse también perpendicularmente a las calles con las que limitan. Sobre estas primeras divisiones del territorio se asentaron edificaciones desarrolladas por autoconstrucción y/o autogestión de los propios habitantes, por lo que se identifican viviendas unifamiliares, en su mayoría de una única planta. Las nuevas tipologías residenciales no introdujeron cambios en los límites de parcelas.

\subsubsection{Límites construidos. Llenos - vacíos}

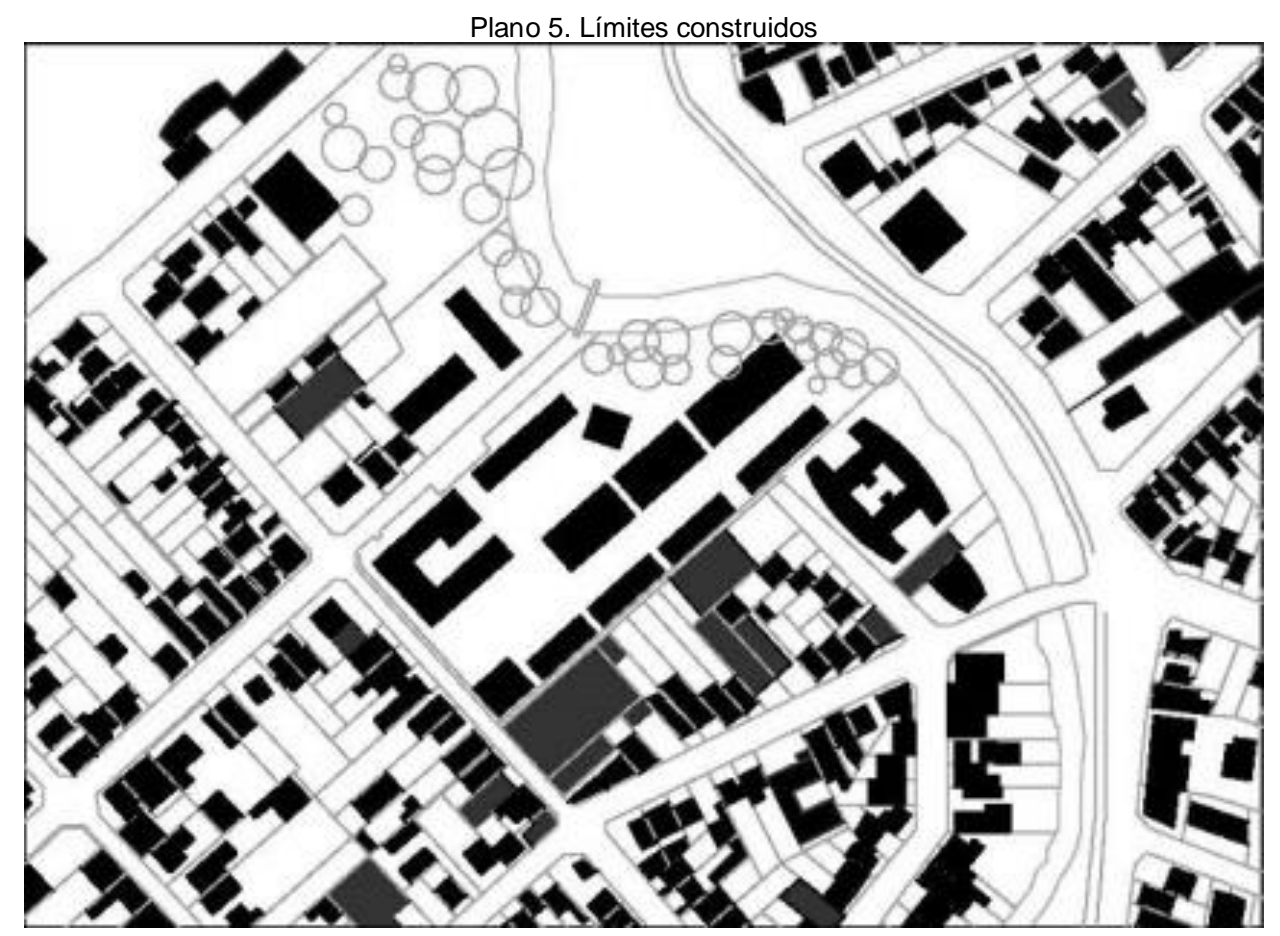

Fuente: elaboración propia (2017), en base a Google Earth

Las escasas edificaciones anteriores a mediados del siglo XX que aún persisten responden a dos lógicas. Aquellas con mayor grado de consolidación se localizan sobre la línea municipal, elevadas por un basamento que las protegía de las crecidas del río, y son de una única planta y de techo plano. También se pueden encontrar algunas viviendas unifamiliares de mediados de siglo, construidas en madera, sobre pilotes, separadas de la línea municipal. La mayoría de las viviendas unifamiliares más recientes tienen un retiro de frente y, según el ancho de los lotes, un retiro lateral. Sobre las grandes parcelas lindantes a río se localizaban edificaciones de uso industrial, logístico y en mayor medida guarderías marinas, edificaciones de grandes superficies, muy sencillas y poco consolidadas, con techos metálicos, y cerramientos con pocas aberturas.

Las edificaciones de madera, ladrillos a la vista o revocadas, pero también los toldos que cubren cocheras o la vegetación, conforman los bordes del espacio urbano que separa lo lleno de lo vacío. Este borde, que se separa de los límites entre la propiedad privada y el espacio público, se conforma por estas diversas texturas, colores y perfumes que acompañan el recorrido, invitando a girar la vista y contemplar estos límites cambiantes y algunas veces difusos. Las edificaciones otras veces se retiran también de los ejes laterales, y nuevamente el límite entre los llenos y vacíos se desdibuja. El trazado ortogonal que propone un horizonte inalcanzable aún para la vista, se quiebra por las calles irregulares en el área, y las texturas y colores cambiantes, los juegos de luces y sombras de los límites porosos, atrae la vista y la desvía de ese infinito, generando situaciones urbanas distintas a cada paso.

Sobre este paisaje heterogéneo se instalaron en la última década, los condominios. Las edificaciones son exentas, alejadas de los límites de las parcelas y sobre la línea municipal se edifican altos muros, acompañados por diversas medidas de seguridad. Estos desarrollos tienen una tipología multifamiliar, de 3 a 5 pisos de altura, como un bloque único o en forma de tiras, en muchos casos con aterrazamientos hacia el río, donde además se ubican los amenities exteriores. 
Plano 6. Límites percibidos

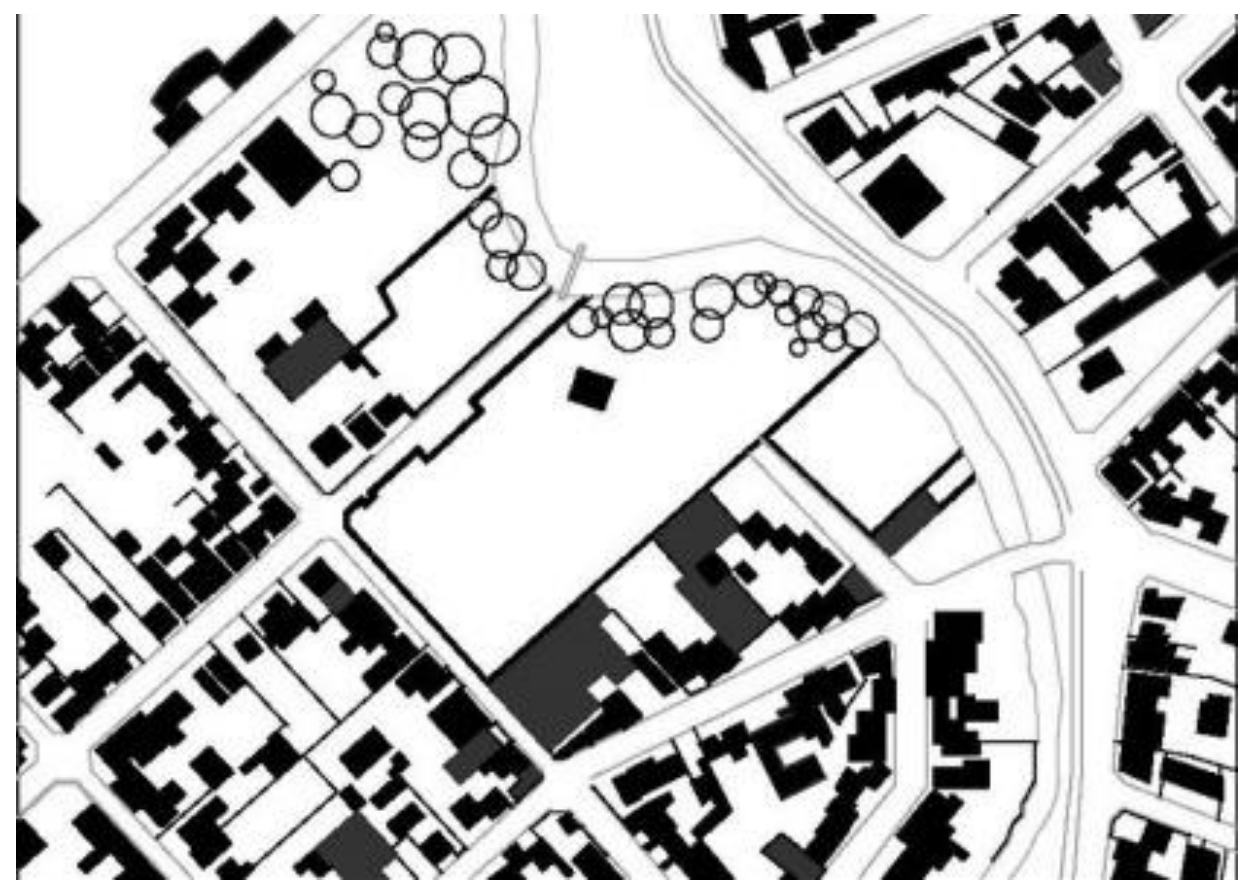

Fuente: elaboración propia (2017), en base a Google Earth

Los retiros de frente de la mayoría de las edificaciones desdobla el límite visual del espacio urbano: las fachadas de las construcciones, y el límite entre lo público y lo privado: la línea municipal.

En el tejido anterior a 1990, el límite entre lo público y lo privado, se materializaba con cercos bajos. Entre ellos y las fachadas de las edificaciones se observan patios o jardines, que amplían el espacio urbano que se visualiza desde la calle. Los cercos bajos y los retiros laterales permiten ver el interior de las parcelas. De este modo, al recorrer estas zonas, el espacio urbano que se puede percibir así como las visuales que se generan, se modifican todo el tiempo, abonando a la idea de diversidad y heterogeneidad que caracteriza al paisaje del AMBA. La repetición de estos interiores que se funden con el exterior pero que no pueden ser atravesados para su uso público, conforma parte de la identidad característica de las zonas suburbanas del AMBA. La relación de estos espacios con el afuera, las veredas amplias y arboladas, son indicios de la forma de habitar estos territorios, de los encuentros cerco de por medio con los vecinos que circulan por la misma calle.

Por el contrario, las nuevas tipologías residenciales proponen una manera muy diferente de materialización del límite entre el adentro y el afuera, intentan disminuir el contacto con la ciudad existente. Entre los emprendimientos y el resto de la ciudad se colocan, entonces, cerramientos, muros con alambres de púa, cámaras de vigilancia y rondas de guardias de seguridad. Pero, además, en muchos casos, la vegetación, aparentemente sin mantenimiento, que invade los muros, o el avance de estacionamientos sobre la vereda, dificultan el paso de peatones en las veredas de los emprendimientos. Así, a pesar de que los emprendimientos suman diseño en el espacio urbano del entorno, estas situaciones parecen una estrategia de separación con la ciudad.

\subsection{Vicente López: torres y edificios de autor}

Hacia fines del siglo XIX, el territorio de Vicente López estaba subdividido en franjas perpendiculares al río, de un ancho entre $160 \mathrm{~m}$ y $200 \mathrm{~m}$, que surgieron de las diversas ventas y sucesiones que fragmentaron las suertes repartidas por Garay. Las quintas se emplazaban sobre la barranca, en su mayoría con un desarrollo paralelo a la costa, extendiendo la posibilidad de visuales al río. Ya a inicios del siglo XX, las actuales avenidas Maipú y del Libertador, así como el FC Mitre y el actual Tren de la Costa, paralelos al río estaban consolidados. 


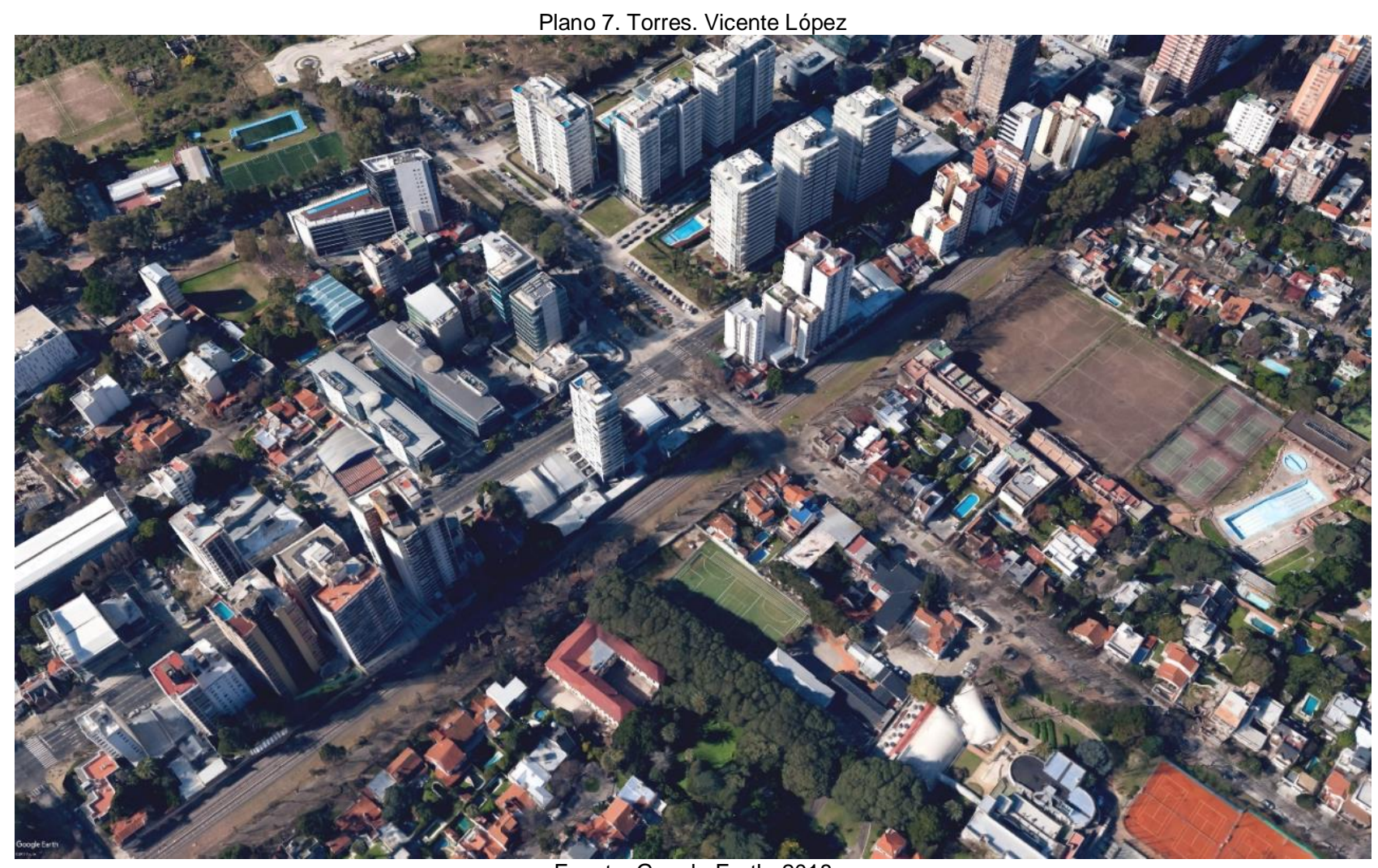

Fuente: Google Earth, 2018

Posteriormente, con la inauguración de una nueva estación entre Olivos y Belgrano, la actual Vicente López, se inició un proceso de loteo. Los antiguos caminos rurales, entre las suertes, que se consolidaron como corredores comerciales a lo largo del siglo XX, así como los caminos del bajo y del alto, perpendiculares a ellos, fijaron el rumbo del nuevo trazado. A inicios de ese siglo, aparecieron los primeros bares, parrillas y vestuarios sobre la costa, mostrando los inicios del balneario de Olivos, con playas de arena que se adentraban alrededor de $400 \mathrm{~m}$ hacia el río, y que con los recientemente inaugurados ferrocarriles, atraían a numerosos visitantes cada fin de semana. Esta ocupación tardía de la costa permitió que muchas de las calles principales se continuaran hasta el río.

Sin embargo, la costa de Vicente López tuvo grandes modificaciones a causa de los rellenos que paulatinamente fueron ganando tierra y alejando al río de la avenida del Libertador. Esta zona, largamente constituida por bañados, fue ocupada paulatinamente por edificaciones poco consolidadas donde se asentaban actividades deportivas y sociales, que iban corriendo sus límites y aumentando su superficie, con el avance de los rellenos. En el plano realizado por la Dirección de Catastro en 1973, se visualizaban sectores a concesionar por privados, ya fuera de la línea de ribera. Este avance de tierras y su indefinida situación dominial se registraron en diversos actos administrativos. En principio, en el acto de transferencia, de la "administración, explotación, uso y goce de la ribera jurisdiccional" que la Provincia de Buenos Aires hizo al Municipio de Vicente López en marzo de 1977, y en la solicitud que sólo unos meses después hizo a la Administración General de Puertos. En este último, se "solicita a la Administración General de Puertos conocer el máximo de avance del río con rellenos, a lo cual esa administración supedita la realización de los rellenos a la autorización de la Dirección Nacional de Construcciones Portuarias y Vías Navegables, que deniega la autorización hasta la realización de los estudios correspondientes".

De este modo, se observan dos situaciones muy diferenciadas divididas por la avenida del Libertador y las vías del ferrocarril Mitre. Ambas se encuentran a una distancia aproximada de $50 \mathrm{~m}$, por lo que entre ellas se conforma una media manzana con parcelas consecutivas de 10 a $12 \mathrm{~m}$ de ancho y frente hacia la avenida.

Entre las avenidas del Libertador y Maipú, se identifica una repetición de manzanas cuadradas, enmarcadas por corredores comerciales, perpendiculares al río, distanciados entre $200 \mathrm{~m}$ y $400 \mathrm{~m}$. Estas arterias, casi en su totalidad, se prolongan hasta el río. Entre la avenida del Libertador y el río, entonces, fragmentos longitudinales, enmarcados por la prolongación de esos corredores, comprenden situaciones muy diversas. Algunos son grandes predios ocupados por usos recreativos y, en algunos casos, militares; otros se 
fraccionan en manzanas subdivididas en parcelas con edificaciones individuales de uso residencial. El tamaño de las manzanas depende de la distancia de las calles que penetran en esta zona. En algunos casos, estos predios se fraccionan nuevamente, abriendo calles paralelas al río. Así, si bien el trazado es regular, con calles que penetran en la zona y algunas sin salida, paralelas a la costa, las manzanas tienen tamaños muy diversos. Lo mismo ocurre con las divisiones parcelarias que se adaptan a las formas de las manzanas pero también a los clubes o depósitos que ocupan lotes de mayor tamaño. Las subdivisiones posteriores, que tienen lugar durante la segunda mitad del siglo XX, se desarrollan en parcelas con dimensiones y superficies muy variables. Sólo se encuentra alguna regularidad en los anchos, que, como se revisó anteriormente, responden a las normativas de distintos momentos históricos, $8.66 \mathrm{~m}, 10 \mathrm{~m}$ y $12 \mathrm{~m}$.

Las edificaciones de uso recreativo son grandes cubiertas metálicas, con cerramientos con pocas aperturas. Sobre la avenida del Libertador, durante las décadas de 1960 y 1970, tuvo lugar un reemplazo de las viviendas por edificios multifamiliares, sobre línea municipal, con locales comerciales en las plantas bajas. Algunas de esas viviendas también fueron reemplazadas o los lotes vacíos fueron ocupados por locales comerciales. Encontramos dos tipos, los relacionados con el rubro automotor se localizan en el fondo de las parcelas dando lugar a una plaza de exhibición hacia la calle. El resto de los comercios se localizan sobre línea municipal. Finalmente, entre avenida del Libertador y el río, las viviendas corresponden fundamentalmente a tres tipos. La mayoría son viviendas unifamiliares de un piso, tipo chalet, que se emplazan con un retiro promedio de $3 \mathrm{~m}$ de línea municipal, dando lugar a pequeños jardines o patios. Luego, sobre la avenida se localizan algunas edificaciones con uno o dos pisos de uso residencial o servicios, sobre una planta baja con locales comerciales. Por último, se identificaron en algunas parcelas puntuales, dos de ellas en la zona de estudio, el desarrollo de varias viviendas individuales, muy precarias, implantadas hacia los ejes medianeros, con un pasillo central que permitía el acceso.

En los últimos diez años, el área se transformó ampliamente, a partir de una serie de acuerdos e instrumentos, corriendo la línea de ribera, permitiendo y promoviendo la construcción de edificios en altura, de perímetro libre, con usos residenciales y de servicios, en la zona entre la avenida del Libertador y el río.

Si bien las grandes parcelas fueron transformando su uso logístico y recreativo a viviendas multifamiliares en las últimas dos décadas, aún persisten los lotes más pequeños con viviendas unifamiliares tipo chalet destinadas a sectores medios.

En este caso, se eligió un recorrido sobre la calle Bartolomé Cruz, de reciente apertura, que se extiende dentro de un área completamente modificada, hasta la calle $\mathrm{H}$. Yrigoyen, boulevard transformado en el marco del proyecto urbano de rehabilitación ribereña, y finaliza sobre la avenida del Libertador, que evidencia los cambios en un corredor comercial fuertemente consolidado previamente. 


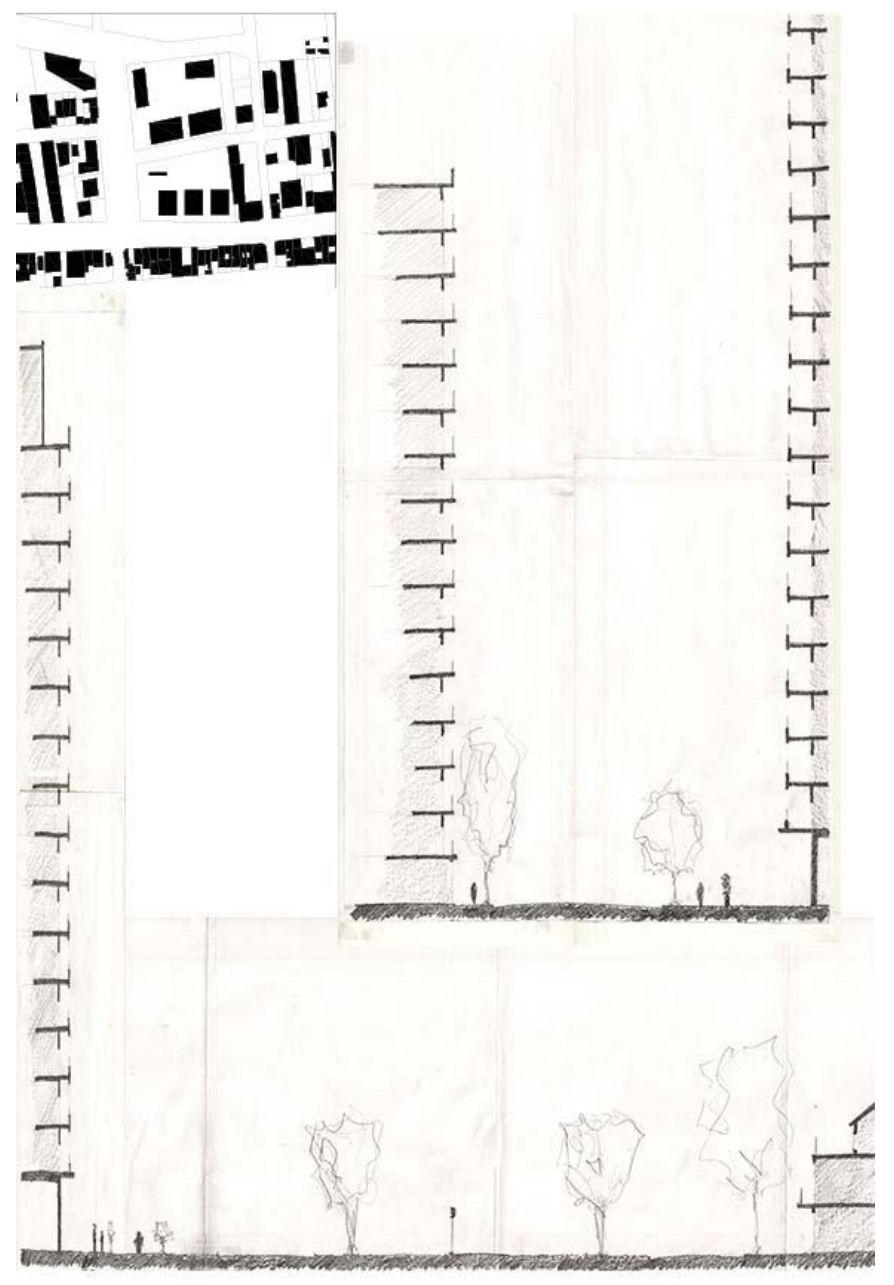

Fuente: elaboración propia (2017)

3.2.1. Límites administrativos. Lo público - lo privado

Plano 9. Límites administrativos

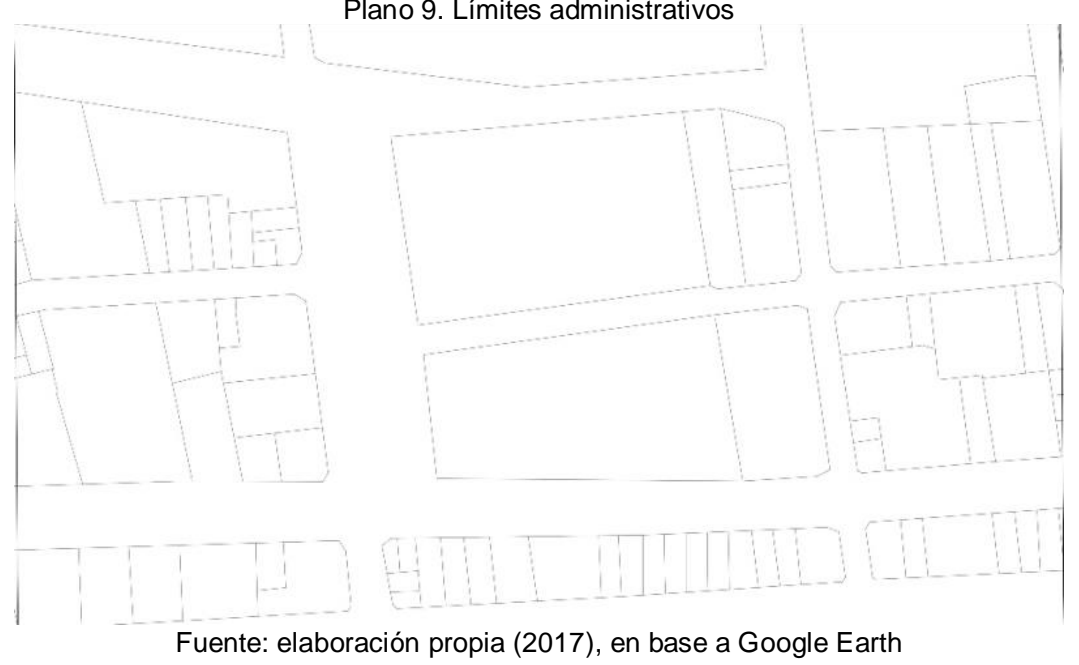


La cercanía al río introduce un nuevo límite administrativo entre lo público y lo privado, la línea de ribera. Una particularidad de esta zona de estudio ha sido el desarrollo continuo de rellenos que, si bien se repiten a lo largo de toda la costa, en Vicente López tuvieron un impacto considerablemente mayor, en particular desde la década de 1970. Por tanto, durante la década de 1990 fue necesario un acuerdo entre la provincia de Buenos Aires y el municipio de Vicente López, que requería fijar una nueva línea de ribera, que dividiría una zona de nuevos parques sobre las tierras públicas de otra con usos residenciales y de servicios. Esto implicaba que la provincia de Buenos Aires realizara una incorporación catastral de las tierras ganadas al río que se encontraran entre la línea de ribera previa y la que se aprobara. De este modo, ese suelo, de rellenos casi en su totalidad ilegales, pasaría a ser de dominio privado.

La zona de estudio es atravesada por la avenida del Libertador y las vías del FC Mitre, que corren en forma paralela entre ellas y el río. Algunas calles perpendiculares penetran el tejido entre la avenida y el río, abriendo la accesibilidad a la costa. Muchas de estas calles, cerradas durante la última dictadura cívicomilitar, fueron recuperadas con el retorno de la democracia.

Por tanto, en principio se puede identificar una jerarquización dentro del trazado regular. La avenida del Libertador y las vías del FC Mitre estructuran el territorio regionalmente. Luego, algunas calles principales tienen un ancho mayor marcando su ingreso al área ribereña. Finalmente, las calles paralelas al río, se interrumpen a ambos lados de la avenida, por la presencia de grandes predios de usos militares (o más ampliamente, de seguridad) y recreativos.

Esto divide la zona en dos franjas paralelas al río. En primer lugar, la zona localizada entre las vías del FC Mitre y la avenida del Libertador. Entre ambos, se alinean una serie de manzanas conformadas por una sola hilera de parcelas consecutivas, de entre 25 y $50 \mathrm{~m}$ de fondo. Los límites longitudinales están dados por las arterias principales que atraviesan las vías. De este modo, el tamaño es variable entre 100 y $300 \mathrm{~m}$. También es diverso el ancho de las parcelas, la mayoría de ellas entre 10 y $12 \mathrm{~m}$, y algunas otras más pequeñas de $8.66 \mathrm{~m}$ o mayores con 18 y $19 \mathrm{~m}$, posiblemente resultantes del englobamiento o la falta de subdivisión de otras parcelas previas. En segundo lugar, las manzanas ubicadas entre la avenida del Libertador y el río, tienen formas regulares, excepto por el borde ribereño que toma la forma de la línea de ribera existente. Desde 2011, el vial costero, arteria vehicular realizada por Vialidad Nacional y el municipio de Vicente López, materializa ese límite, antes continuamente cambiante. En estas manzanas se alternan grandes lotes y pequeñas parcelas. Por un lado, las grandes parcelas tienen usos recreativos, de seguridad, $y$, en menor medida, logísticos. Las medidas de estos lotes son variables. Se pueden observar desde parcelas de $40 \times 80 \mathrm{~m}$ hasta otras de $50 \times 160 \mathrm{~m}$. La única regularidad que se puede observar en ellas es que tienen un desarrollo longitudinal, con la mayor medida perpendicular a la costa, correspondiendo a las subdivisiones que fueron teniendo las "suertes" a lo largo del tiempo. Por otro lado, el resto de las parcelas que alojan actividades residenciales tienen superficies menores, que rondan los $200 \mathrm{~m} 2$ en los lotes de esquinas y $400 \mathrm{~m} 2$ en los de mitad de la cuadra. Si bien la forma y superficie de estas parcelas son muy diversos, tanto a causa de la morfología de las manzanas como de los grandes lotes de equipamientos que se localizan en ellas, se pueden encontrar dos características que se repiten. Por un lado, la mayoría de estas parcelas tienen un ancho aproximado de $12 \mathrm{~m}$. Por otro, se identifican zonas con parcelas de dimensiones semejantes que podrían corresponder a fragmentos subdivididos al mismo tiempo.

Las parcelas de mayor tamaño han resistido menos a los cambios recientes, por lo que sus edificaciones y usos fueron los primeros en ser reemplazados. Los nuevos emprendimientos se localizaron en estas grandes parcelas sin realizar modificaciones, excepto el caso de aquellos ubicados sobre la prolongación de la calle Bartolomé Cruz que fue abierta al momento de realizar las cesiones correspondientes.

\subsubsection{Límites construidos. Llenos - vacíos}




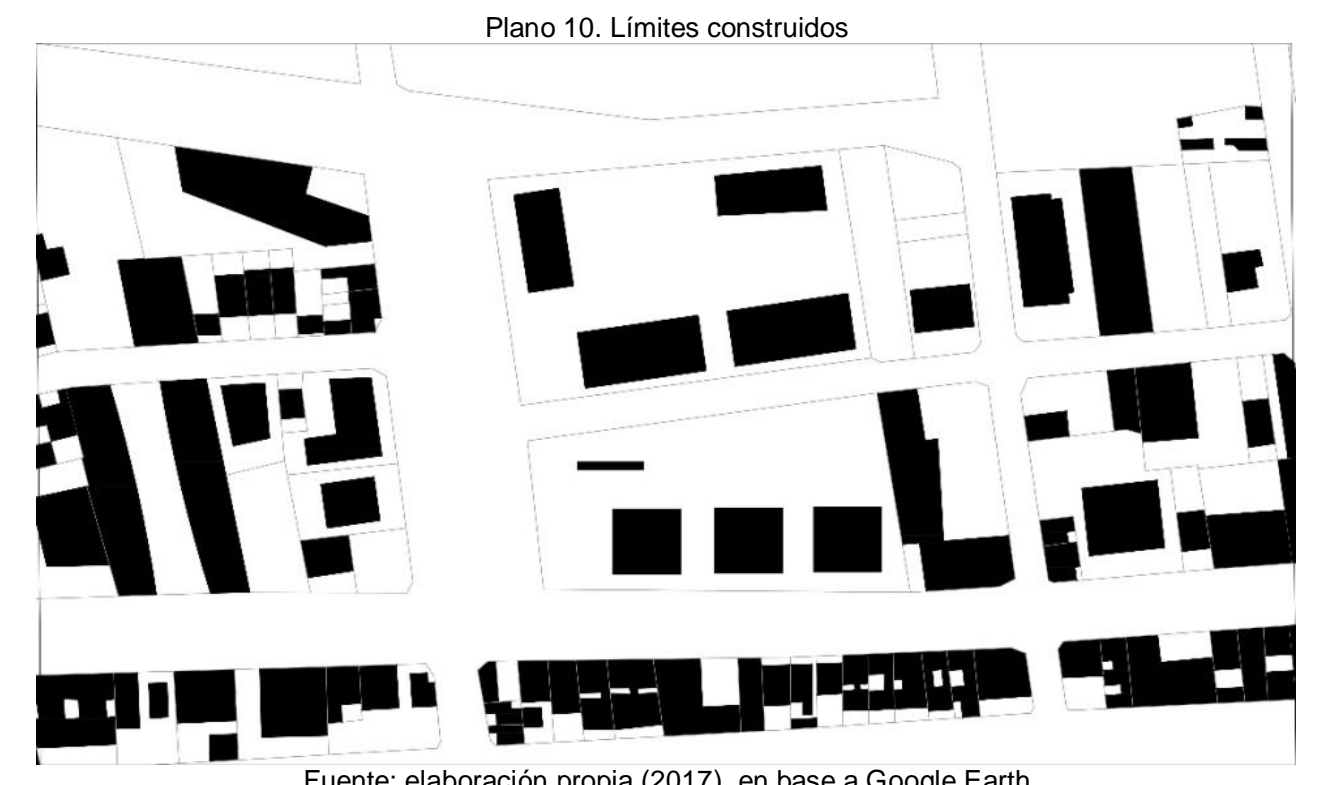

Fuente: elaboración propia (2017), en base a Google Earth

El área presenta una heterogeneidad edilicia que evidencia los diversos procesos que se fueron dando en distintos momentos. Pero, además, se identifican dos tipos de construcciones muy distintas sobre la avenida del Libertador y en los tejidos internos. Esta diferencia tiende a desaparecer con las recientes transformaciones del área.

Por un lado, a lo largo de la avenida del Libertador se identifican dos tipos de construcciones. Algunas de uno o dos pisos, que contienen actividades comerciales en planta baja y oficinas o vivienda en la planta alta, por lo que se localizan sobre línea municipal, con fachadas permeables por grandes aberturas. Aquellas construcciones que más resaltan son los edificios en altura. Pueden identificarse, mayoritariamente, tres tipos. Las edificaciones realizadas entre las décadas de 1960 y 1990 son edificios de vivienda entre medianeras, sobre línea municipal, con un desarrollo de alrededor de 9 pisos de vivienda multifamiliar y planta baja de uso comercial con grandes aberturas hacia la calle. Sin embargo, en los últimos años, a partir de cambios en la normativa urbanística local se permitió duplicar esa altura. Estas nuevas construcciones tienen un desarrollo de planta baja más 18 pisos, exclusivamente de uso residencial. Por tanto, interrumpen la continuidad comercial que se desarrollaba en las plantas bajas sobre la avenida y que contribuía a una circulación peatonal fluida por este corredor. Más aún, algunos de estos edificios se retiran de la línea municipal, y aquellos que se localizan en grandes parcelas, son de perímetro libre con un cerco perimetral. De este modo, las nuevas edificaciones interrumpen, de diversas maneras, la continuidad morfológica y de usos del corredor de avenida del Libertador, uno de los ejes comerciales más consolidados y dinámicos de la zona norte.

Por otro lado, en los tejidos interiores, se encontraban predominantemente dos usos que correspondían a particularidades en la relación entre las construcciones y las parcelas. Los usos recreativos se materializaban con grandes recintos con techos metálicos, cerramientos con pocas aberturas, localizados sobre línea municipal. Otros de mayor superficie tenían pocas edificaciones esparcidas en el terreno, asociadas a las diversas actividades deportivas que se desarrollaban a cielo abierto. Estas actividades, emplazadas en grandes parcelas, son las que han sufrido mayores transformaciones. En parcelas de menor tamaño se localizan, aún, actividades residenciales. Las viviendas unifamiliares de tipo chalet, de uno o dos pisos de altura, entre medianeras, tienen un retiro de línea municipal de $3 \mathrm{~m}$ a $6 \mathrm{~m}$, donde se desarrollan patios y jardines. Otro tipo de viviendas, que tienden a desaparecer de la zona, son hileras de edificaciones de un piso de altura, que se localizan sobre los ejes medianeros con un pasillo central, y separadas entre sí, dejando patios entre las viviendas. Finalmente, las construcciones más recientes, tanto de usos residenciales como de oficinas, se desarrollan en altura. Si bien las modificaciones en la normativa urbanística sólo permitían edificaciones de 18 pisos más planta baja, sobre la avenida del Libertador, posteriormente, se permitieron algunas excepciones, por lo que se observan edificios de esas alturas en los tejidos interiores. Estas construcciones son de perímetro libre, y, a diferencia de los edificios residenciales, no siempre tienen un muro opaco en los límites del lote, en algunos casos tienen cercos de rejas.

\subsubsection{Límites percibidos. Adentro - afuera}




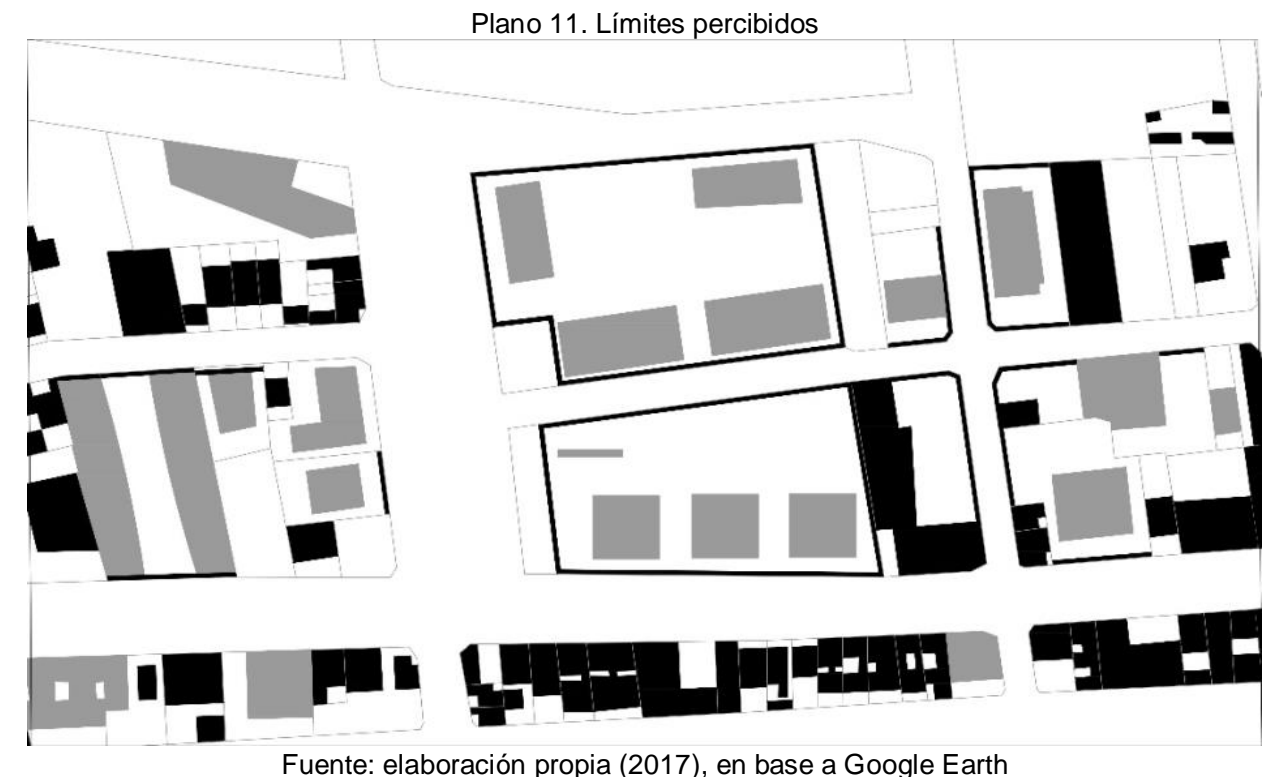

Nuevamente, las particularidades de los límites entre el adentro y el afuera, marcan dos situaciones muy diferenciadas.

Tanto en las viviendas unifamiliares en los tejidos interiores, como en las viviendas multifamiliares y comercios, sobre la avenida del Libertador, los límites entre el adentro y el afuera tiene matices. Las viviendas unifamiliares tipo chalets, al retirarse de la línea municipal, y materializar ese límite con cercos bajos, conforma un patio o jardín que actúa, como en otras zonas de la costa norte, con características similares, un espacio de transición entre lo público y lo privado. Los locales comerciales, tanto en edificaciones individuales como cuando conforman las plantas bajas de usos residenciales multifamiliares, a causa de sus propios objetivos, se localizan sobre línea municipal, con grandes ventanales, que intentan desmaterializar al máximo el límite entre el adentro y el afuera. Entonces, de forma más fragmentada en los tejidos interiores, y más claramente, en el corredor comercial, a lo largo del espacio público de la calle, se emplaza una sucesión de espacios de transición entre el adentro y el afuera. En el caso de las áreas interiores, la sucesión de patios delanteros, aun cuando son interrumpidos por las grandes parcelas de los clubes, componen fragmentos de tejido suburbano. En aquellos breves momentos del recorrido donde confluyen algunas viviendas unifamiliares, se pueden observar las torres que emergen alrededor. Allí se explicita el desajuste entre la escala del tejido suburbano y la de las edificaciones recientes.

Esta zona, como se ha dicho, fue escenario de grandes transformaciones. Cuadras, e incluso manzanas, han sido modificadas completamente en la última década. El impacto de estos cambios tanto en el corredor comercial como en los tejidos suburbanos interiores, ha sido fundamentalmente relevante en las nuevas "fachadas" urbanas que se conformaron. En los edificios de viviendas multifamiliares u oficinas que se retiran de la línea municipal, el límite entre el adentro y el afuera, se materializa a través de muros opacos o cercos vivos (sobre rejas). Por tanto, a causa de la considerable superficie transformada recientemente, que guarda estas características, se pueden observar cuadras donde a ambos lados de la calle se levantan muros de al menos $2 \mathrm{~m}$ de altura. Esto cambia completamente la experiencia de la calle. Las fachadas urbanas permeables, con espacios de transición entre el adentro y el afuera, fue reemplazada por estos altos muros. Por tanto, la calle sólo queda como lugar de paso, casi un túnel a cielo abierto.

También en algunos casos, las edificaciones en altura, de reciente construcción se retiran de línea municipal sobre la avenida del Libertador. En este caso, el impacto es aún más visible puesto que los muros interrumpen la continuidad de un zócalo comercial. Finalmente, pocos edificios de oficinas se retiran de línea municipal, sin materializar la línea municipal. Es decir, la zona entre ésta y la fachada de los edificios es un espacio abierto, de acceso público. Sin embargo, se encuentran en un nivel más elevado que la vereda, con cercos bajos continuos, por lo que sólo se puede acceder a estos espacios en algunos lugares determinados. Y, finalmente, la vereda se confunde con el espacio de acceso vehicular. Por tanto, esos espacios abiertos que podrían "ganarse" para la ciudad, así como las veredas, obligatoriamente de uso público, son de difícil acceso para quienes circulan en el área. 


\section{CONTINUIDADES Y DISCONTINUIDADES URBANAS}

El recorrido por dos zonas con situaciones de transformación tan diversas permitió explicitar algunas cuestiones.

Los tejidos suburbanos del AMBA se caracterizaron por una diversidad de situaciones dadas por las particularidades morfológicas de los trazados y parcelamientos, por los cambios en la normativa urbanística que ocasiona modificaciones en los mismos, así como por las particularidades de los procesos de autoconstrucción y/o autogestión de las edificaciones.

De esta manera, a pesar de los cambios en sus formas y superficies, las "fachadas" urbanas se conforman por una continuidad de esos espacios a lo largo de las calles, una sucesión de capas que materializan los diversos límites administrativos (manzanas y parcelamientos), construidos (edificaciones) y percibidos (materialidad de la línea municipal). Así, estas "fachadas", más que una línea continua y homogénea como se observa en otras ciudades, comprenden espacios de transición que enmarcan la calle, abriendo y cerrando el espacio urbano, generando visuales siempre cambiantes. Esto transforma cada calle o cada cuadra en lugares, en espacios con una fuerte identidad distintiva; la calle es lugar de paso y de encuentro, a la vez.

Sin embargo, estos paisajes tan diversos conformados por espacios públicos que actuaban como extensión de la vida cotidiana, con la llegada de los nuevos productos residenciales son escenario de un proceso de homogeneización, no sólo social o de usos sino también formal. Estos límites que se conformaban a través de capas (los cercos bajos, los frentes de las edificaciones, o los muros medianeros) son invisibilizados por los desarrollos inmobiliarios recientes a través de altos muros que se materializan sobre la línea municipal. En todo caso, podemos encontrar capas verticales, muros de ladrillo, cercos electrificados, cámaras de vigilancia, que se suceden para impedir la visión y la entrada de un "otro" peligroso.

El recorte analítico a partir de recorridos urbanos permite dar cuenta de la perspectiva de quienes habitan la ciudad. En ese sentido, se identificaron características muy diversas entre el espacio urbano de los tejidos tradicionales del AMBA y aquellos resultantes de las transformaciones recientes. Asimismo, las formas urbanas nos remiten a diversas maneras de habitar la ciudad. Los cercos bajos, los patios y jardines delanteros, la visión del interior de la parcela por los retiros laterales, aluden a una particular relación entre el adentro y el afuera. Estas características del espacio público, la porosidad de las "fachadas" de las áreas suburbanas, invitan a las conversaciones entre vecinos, a los encuentros en las "galerías" naturales que se arman bajo los árboles. Por tanto, se desdibuja el límite con el afuera, se resignifica la relación entre lo público y lo privado, acercando la calle, asumiéndola, en la práctica, como una extensión del adentro.

En contraposición, los nuevos desarrollos residenciales tienen diferencias tipológicas, de densidades; sin embargo, desde el espacio público sólo se observan los muros que los encierran. Estos cercos opacos, muchas veces, en realidad, capas de muros que se suceden, son estrategias de separación con el resto de la ciudad. En las zonas de mayor transformación, la escala de los emprendimientos, como en Vicente López, la situación se invierte. La prolongación de muros a ambos lados de la calle, por varias cuadras, parece, por el contrario, encerrar a quienes circulan por el espacio público. Así, el espacio urbano se estrecha, se limita la visual pero también se homogeneiza el paisaje. Las capas de colores y texturas diversas, los juegos de luces y sombras de los distintos volúmenes, los huecos en las fachadas, son reemplazados por altos y lisos muros. Esta situación tiene un impacto mayor cuando estas nuevas tipologías residenciales se localizan en áreas urbanizadas, con gran consolidación. Puesto que los procesos de la última década, si bien continúan en las periferias y los corredores comerciales, tienen un gran impacto en los tejidos interiores, la presencia de los muros y la homogeneización de las "fachadas" urbanas modifican más ampliamente, también, las formas de habitar el espacio urbano.

En este escenario, no aparece la ciudad, y, entonces, se desdibuja el espacio urbano como articulador, como facilitador de la interacción social. Así, el espacio que experimentan quienes circulan diariamente, desde el cual vivirán la ciudad, se conforma como lo residual, aquello que queda luego de la materialización de los proyectos individuales desarrolladas por el sector inmobiliario. Por tanto, conocer la morfología de estos nuevos productos residenciales, los bordes que se conforman entre ellos y la ciudad, y cómo impactan en el espacio urbano, contribuye a repensar los instrumentos normativos que regulan su producción. 


\section{BIBLIOGRAFÍA}

Castells, M. (1995). La ciudad informacional: tecnologías de la información, reestructuración económica y el proceso urbano_regional, Madril, España: Editorial Alianza.

Ciccolella, P. y Vecslir, L. (2012). Dinámicas, morfologías y singularidades en la reestructuración metropolitana de Buenos Aires. Revista Iberoamericana de Urbanismo (8) 23 - 41. http://www.riurb.com/n8/08_01_Ciccolella.pdf

Cullen, G. (1974). El paisaje urbano, tratado de estética urbanística. Barcelona, España. Editorial Blume.

De Mattos, C. (2010). Globalización y metamorfosis urbana en América Latina. Santiago de Chile: Revista de geografía norte grande.

Font, A., Llop, C., Vilanova, J. M. (1999). La Construcció del Territori Metropolità. Morfogènesi de la regió urbana de Barcelona. Barcelona: Editorial Mancomunitat de Municipis de l'Àrea Metropolitana de Barcelona.

Indovina. F. (2004). Ciudad Difusa y el Archipiélago metropolitano. Revista CET: Cidades- Comunidades e Territórios Jun. 2009, n.0 18, pp. 13-28.

Llop Torne. J. (2008). Guía metodológica: Análisis de la ciudad latinoamericana. Atlas urbano.

Novick, A. (2001). La costa en proyectos. SCA La ribera (2001).

Quan Lui, Ziyu Tong (2016). The morphological relationship between the plot pattern and street facade in the new área of Nawjine, China. G. Strappa, A. Amato, A. Camporeale, (ed). City as organism: new visions of urban life. (Vol. II, 1130-1140).

Ryan, B. (2005). Morphological change through residential redevelopment: Detroit, 1951-2000. Urban Morphology 10 (1), 5-22

https://dusp.mit.edu/cdd/publication/morphological-change-through-residential-redevelopment

Sabaté, J. (2004). De la preservación del patrimonio a la ordenación del paisaje. Urbano 7 (10) 42 - 49.

Sabate, J. (2013). Algunos retos del proyecto territorial. En Territorio, proyectos e infraestructura para el AMBA. Buenos Aires: Observatorio Metropolitano - CPAU. Disponible en http://observatorioamba.org/publicaciones/tpiamba/3/\#zoom=z

Sainz, G. (2006). El proyecto urbano en España: Genesis y desarrollo de un urbanismo de los arquitectos. Universidad de Sevilla, España.

Sassen, S. (1999). La ciudad global: Nueva York, Londres, Tokio, Buenos Aires, Eudeba, 1999, 458 pp. Título original: The Global City: New York, London and Tokyo, Princeton, Nueva Jersey, Princeton University Press, 1991.

Secchi, B. (2014). El espesor de la calle. En A. M. Ramos. La calle en 30 autores contemporáneos y un pionero. Barcelona: Iniciativa Digital Politécnica.

Soja, E. (2008). Postmetrópolis Estudios críticos sobre las ciudades y las regiones. Madrid, España. Traficantes de Sueños C/Embajadores 3528012 Madrid. Tlf: 915320928 e-mail:editorial@traficantes.net http://traficantes.net

Sola-Morales, I. (2002). Territorios. Barcelona: Editorial Gustavo Gili.

Vernez Moudon, A. (1998). Urban morphology as an emerging interdisciplinary field. Urban Morpholog 2.1, 